\title{
Properties and Expression of a Multidrug Efflux Pump AcrAB-KocC from Klebsiella pneumoniae
}

\author{
Dai-Wei Li, ${ }^{a}$ Motoyasu Onishi, ${ }^{a}$ Takanori Kishino, ${ }^{b}$ Taira Matsuo, ${ }^{b}$ Wakano Ogawa, ${ }^{a}$ \\ Teruo KURODA, ${ }^{b}$ and Tomofusa TsuchiYA ${ }^{*, a}$ \\ ${ }^{a}$ Department of Molecular Microbiology, Graduate School of Medicine, Dentistry and Pharmaceutical Sciences, Okayama \\ University; and ${ }^{b}$ Department of Genome Applied Microbiology, Graduate School of Medicine, Dentistry and \\ Pharmaceutical Sciences, Okayama University; Tsushima, Okayama 700-8530, Japan.
}

Received December 18, 2007; accepted January 24, 2008; published online January 25, 2008

\begin{abstract}
We previously reported that we had cloned genes responsible for multidrug resistance from the chromosomal DNA of Klebsiella pneumoniae MGH78578 using a drug-hypersusceptible Escherichia coli strain as a host. One of the recombinant plasmids pETV6 conferred resistance to host cells against a wide range of antimicrobial agents, dyes and detergents. It was revealed that this plasmid carried the $a c r B_{K p}$ gene and a part of the $a c r A_{K p}$ gene coding for a multidrug efflux pump belonging to the RND family. We cloned the whole $a c r A_{K p} B_{K p}$ operon of $K$. pneumoniae and characterized the pump. The AcrAB pump utilized TolC as an outer membrane component in cells of $E$. coli. Elevated energy-dependent efflux of ethidium was observed with cells possessing $\operatorname{Acr}_{\mathrm{Kp}} \mathrm{B}_{\mathrm{Kp}}$ TolC. We cloned a gene coding for an ortholog of TolC from chromosomal DNA of $K$. pneumoniae, and designated it $k$ ocC. It seems that the $\operatorname{Acr} A_{K p} B_{K p}-K o c C$ complex functions as a potent multidrug efflux pump in $K$. pneumoniae. We observed a higher level of expression of acr $A_{K p}$ in $K$. pneumoniae MGH78578, a multidrug resistant strain, compared with ATCC10031, a drug susceptible strain.
\end{abstract}

Key words multidrug efflux pump; AcrAB-KocC; resistance nodulation cell-division; drug resistance; Klebsiella pneumoniae

A great many people in the world die of pneumonia every year according to the data by the World Health Organization (http://www.who.int/whr/2004/annex/en/index.html). Klebsiella pneumoniae is one of the causative agents of bacterial pneumonia. K. pneumoniae also causes infections in the respiratory tract, urinary tract and blood stream. ${ }^{1,2)}$ Increasing number of $K$. pneumoniae isolates that show resistance against multiple drugs have been reported in the world. ${ }^{3)}$ Thus, it is becoming difficult to treat patients infected with multidrug resistant strains of $K$. pneumoniae by using antibacterial agents.

Multidrug efflux pumps play a major role in multidrug resistance in bacteria by extruding a wide variety of antimicrobial agents, including antibiotics, dyes, antiseptics and detergents. Over-expression of genes for multidrug efflux pumps results in elevated resistance of bacteria against multiple drugs, and is a serious problem in the clinical setting. ${ }^{4)}$ There are several types of multidrug efflux pumps in bacteria. ${ }^{5}$ Among the several types of known efflux pumps, the resistance nodulation cell-division (RND)-type efflux pumps play a major role in the multidrug resistance in Gram-negative bacteria. $^{6-9)}$

The AcrAB-TolC pump of Escherichia coli is one of the most potent multidrug efflux pumps and is the best characterized RND-type multidrug efflux pump in bacteria. ${ }^{10-12)}$ Disruption of the $a c r A B$ or tolC results in great increases in drug susceptibilities in E. coli..$^{9,13)}$ Therefore it seems that AcrABTolC is a principal pump contributing to the intrinsic resistance in $E$. coli against multiple antimicrobial agents.

The RND-type pumps are tripartite, consisting of an inner membrane protein, an outer membrane protein and a periplasmic linker (fusion) protein. Deletion of any one of these three components results in the loss of pump activity. ${ }^{9,13,14)}$ It is thought that RND-type efflux pumps utilize the proton-motive force to extrude substrates from cells. Interest- ingly, several pumps in the RND family extrude $\beta$-lactams, which inhibit synthesis of peptidoglycan in the extracellular periplasmic space. ${ }^{15,16)}$

The $\operatorname{acr} A B$ genes are in an operon in E. coli, and their expression is negatively regulated by AcrR. ${ }^{17)}$ The $a c r R$ gene is located just upstream of the $a c r A B$ locus. Another transcriptional regulatory factor, MarA, also regulates the expression of the $a c r A B$ operon in $E$. coli, and over-expression of marA elicits elevated expression of $a c r A B$ and results in elevated resistance of the cells against multiple antimicrobial agents. ${ }^{18)}$

Orthologs of AcrAB have been reported in many bacteria of the Enterobacteriaceae family. ${ }^{19-23)}$ Domenech-Sanchez et al. suggested a relation between quinolone resistance and the AcrAB ortholog in $K$. pneumoniae. ${ }^{24)}$ Mazzariol et al. reported that the $\operatorname{acr} A B$ ortholog has been over-expressed in a clinically isolated quinolone resistant strain of $K$. pneumoniae. $^{25)}$

We previously reported on the cloning of many genes responsible for multidrug resistance from the chromosomal DNA of $K$. pneumoniae MGH78578, a clinically isolated multidrug resistant strain. ${ }^{26)}$ One of the genes responsible for multidrug resistance was $a c r B_{K p}$. To distinguish between $E$. coli AcrAB and its ortholog in $K$. pneumoniae, we describe here the ortholog as $\mathrm{AcrA}_{\mathrm{Kp}} \mathrm{B}_{\mathrm{Kp}}$ and their genes $\operatorname{acr} A_{K p} B_{K p}$. Here we report on the gene cloning and the properties of the $\operatorname{Acr}_{\mathrm{Kp}} \mathrm{B}_{\mathrm{Kp}}$ pump from $K$. pneumoniae, and expression of $\operatorname{acr} A_{K p}$ in K. pneumoniae cells.

\section{MATERIALS AND METHODS}

Bacterial Strains and Growth The bacterial strains and plasmids used in this study are listed in Table 1. K. pneumoniae MGH78578 was kindly provided by Dr. Michael McClelland of the Sidney Kimmel Cancer Center in San Diego, 
Table 1. Bacterial Strains and Plasmids Used in This Study

\begin{tabular}{|c|c|c|}
\hline \multicolumn{2}{|c|}{ Bacterial strain or plasmid } & \multirow[t]{2}{*}{ Reference } \\
\hline K. pneumoniae & & \\
\hline MGH78578 & A clinical isolate showing multidrug resistance & \\
\hline ATCC10031 & An ATCC collection & \\
\hline \multicolumn{3}{|l|}{ E. coli } \\
\hline KAM32 & Deletion mutant of $a c r B$ and $y d h E$ & 19) \\
\hline KAM33 & Deletion mutant of $a c r A B$ and $y d h E$ & 28) \\
\hline KAM43 & Deletion mutant of acrAB, tolC and $y d h E$ & 28) \\
\hline \multicolumn{3}{|l|}{ Plasmids } \\
\hline pSTV28 & Vector & TaKaRa Co. \\
\hline pETV6 & pSTV28-derived recombinant plasmid carrying $a c r B_{K n}$ & This work \\
\hline pETV62 & pSTV28-derived recombinant plasmid carrying $\operatorname{acr} A_{K V} B_{K p}$ & This work \\
\hline pKTC44 & pSTV28-derived recombinant plasmid carrying kocC $C^{-\kappa p}$ & This work \\
\hline pSET2 & pSTV29-derived recombinant plasmid carrying tolC & This work \\
\hline pBR322 & Vector & \\
\hline pETV63 & pBR322-derivatived recombinant plasmid carrying $a c r A_{K p} B_{K p}$ & This work \\
\hline
\end{tabular}

CA, U.S.A.. K. pneumoniae ATCC10031 was purchased from American Type Culture Collection. E. coli KAM32, KAM33 and KAM43 were constructed in our laboratory. Cells were grown in $\mathrm{L}$ medium (1\% polypeptone, $0.5 \%$ yeast extract and $0.5 \% \mathrm{NaCl}, \mathrm{pH} 7.0$ ), except for measurement of minimum inhibitory concentration (MIC), at $37^{\circ} \mathrm{C}$ under aerobic conditions. Growth of cells was monitored turbidmetrically at $650 \mathrm{~nm}$.

Gene Disruption in $\boldsymbol{E}$. coli Gene disruption was performed in $E$. coli by the method of Datsenko et al. ${ }^{27)}$ The details of disruption of $a c r A B$ and tolC in E. coli were described previously. ${ }^{28)}$

Cloning of $\boldsymbol{a c r} \boldsymbol{B}_{K \boldsymbol{p}}$ and $\boldsymbol{a c r} \boldsymbol{A}_{\boldsymbol{K}}$ We previously reported the cloning of genes responsible for multidrug resistance from the chromosomal DNA of $K$. pneumoniae MGH78578. ${ }^{26)}$ A recombinant plasmid, pETV6, is one of the candidate plasmids. We found that pETV6 carries $a c r B_{k p}$ and a part of $a c r A_{K p}$. A plasmid pETV62 carrying whole $\operatorname{acr} A_{K p} B_{K p}$ was constructed by the following method. Primers for amplification of $a c r A_{K p}$ were acrAKP-F and acrAKP-R (Table 2). Polymerase Chain Reaction (PCR) was performed with a PTC-100TM Programmable Thermal Controller (MJ Research, Inc.). A $0.94-\mathrm{kbp}$ PCR product containing the whole $a c r A_{K p}$ gene and a part of $a c r B_{K p}$ was generated using chromosomal DNA from K. pneumoniae MGH78578 as template under the following PCR conditions: initial denaturation of 2 min at $94^{\circ} \mathrm{C}$, followed by 35 cycles of $15 \mathrm{~s}$ at $94^{\circ} \mathrm{C}$, $30 \mathrm{~s}$ at $51^{\circ} \mathrm{C}, 1 \mathrm{~min}$ at $68^{\circ} \mathrm{C}$. The amplified PCR fragment was digested with endonucleases SalI and $A f l \mathrm{II}$, and ligated with pETV6 digested with the same restriction enzymes. Cells of E. coli KAM33 lacking acrAB were transformed with the resulting plasmid, and the transformants were selected on L agar plates containing $20 \mu \mathrm{g} / \mathrm{mg}$ chloramphenicol. The resulting plasmid is pETV62. Another plasmid pETV63 was constructed as follows. pETV62 was digested with SmaI and SphI, and resulting DNA fragment with 4.7kbp was ligated to pBR322 digested with EcoRV and SphI. pETV62 is a pSTV28-based plasmid carrying acr $A_{K p} B_{K p}$, and pETV63 is a pBR322-based plasmid carrying $\operatorname{acr} A_{K p} B_{K p}$.

Cloning of kocC Gene of $K$. pneumoniae The kocC gene was amplified from chromosomal DNA of $K$. pneumoniae MGH78578 using KOD Plus DNA polymerase (Toyobo
Table 2. Primers Used in This Study

\begin{tabular}{cl}
\hline \hline Primer name & \multicolumn{1}{c}{ Primer sequence } \\
\hline acrAKP-F & 5'-GCTGTCGACGGTTAATGACTTTACAGAGG-3' \\
acrAKP-R & 5'-ACATCCGAGAATTCCAGCGT-3' \\
kocC primer 2 & 5'-CGCTAAAGTACTCACAACAAGGAATGCAAATG-3' \\
(Scal) & \\
kocC primer 3 & 5'-CATCACAGATGCATAATTACTGACGGAACG-3' \\
$\begin{array}{l}\text { (EcoT22I) } \\
\text { tolC forward }\end{array}$ & 5'-TTTTGTCGACATCGCGCTAAATACTGCTTC-3' \\
primer & \\
tolC reverse & 5'-CCCGAATTCGAAGCCCCGTCGTCGT-3' \\
primer & \\
acrA-F(RT) & 5'-GTCCTCAGGTCAGTGGCATTA-3' \\
acrA-R(RT) & 5'-ATTGCTCTGCTGCGCCGTT -3' \\
kocC-F(RT) & 5'-TCAGGTTTACCAGCAGGCAC-3' \\
kocC-R(RT) & 5'-GCGCGCCATTTCGACATATC-3' \\
marA Fw & 5'-GTGGATCGAGGATAACCTGG-3' \\
marA Re & 5'-TACTCTGCTTGAGCTTCTGC-3' \\
ramA Fw & 5'-TTGATACTATCGTCGAGTGG-3' \\
ramA Re & 5'-CTTCCTTTCGCGAATATAGC-3' \\
uncB Fw & 5'-AGCGTTGCTAAGAAAGCGAC-3' \\
uncB Re & 5'-AGGAAGACCCAGACGAACAC-3' \\
\hline &
\end{tabular}

Co.) for 35 reaction cycles, with each cycle consisting of $15 \mathrm{~s}$ at $94{ }^{\circ} \mathrm{C}, 2 \mathrm{~min} 30 \mathrm{~s}$ at $68^{\circ} \mathrm{C}$. The primers used were kocC primer $2(S c a \mathrm{I})$, containing a $S c a \mathrm{I}$ restriction site, and kocC primer 3 (EcoT22I), containing an EcoT22I restriction site (Table 2). The amplified DNA fragment containing the kocC gene was ligated to a vector plasmid pSTV28 digested with $S c a \mathrm{I}$ and PstI. The resulting recombinant plasmid carrying the $k o c C$ gene is pKTC44.

Cloning of tolC Gene of $\boldsymbol{E}$. coli The tolC gene was amplified without its promoter region by using the tolC forward primer and the tolC reverse primer (Table 2) using chromosomal DNA of E. coli TG1 as the template. The length of the PCR product was confirmed by $1 \%$ agarose gel electrophoresis, and the product was purified by GENECLEAN II kit (Qbiogene). The DNA fragment was digested with EcoRI, and then ligated with a vector pSTV29 digested with SmaI and EcoRI. The resulting plasmid is pSET2. The nucleotide sequence of the insert region in pSET2 was determined by the dideoxy chain termination method. We found no error in the sequence. 
Determination of MIC The MICs of various antimicrobial agents were determined in Mueller-Hinton broth (Difco, Sparks, U.S.A.) by the two-fold dilution method. ${ }^{29)}$ Cells in the test medium $\left(10^{5}\right.$ cells $\left./ \mathrm{ml}\right)$ were incubated at $37^{\circ} \mathrm{C}$ for $24 \mathrm{~h}$, and the growth was subsequently judged. We measured the MICs three times and obtained the same results.

Ethidium Transport Assay The assay was performed as described previously ${ }^{30}$ at $37^{\circ} \mathrm{C}$. Ethidium bromide was added to cell suspension at a final concentration of $10 \mu \mathrm{M}$.

RNA Preparation and Reverse Transcriptase (RT)PCR Analysis RNA was isolated from cells harvested at the exponential phase of growth by using an RNeasy mini kit (QIAGEN). Cell lysate was treated with the QIA shredder column before the RNeasy column and treated with RNaseFree DNase (Qiagen Inc., U.S.A.) according to the manufacturer's protocol.

Quantitative real-time RT-PCR was performed with Real Time One Step RNA PCR Kit (TaKaRa Bio Inc.) using the following pairs of oligonucleotides (Table 2); acrA-F(RT) and acrA-R(RT) for acrA, marA Fw and marA Re for marA and ramA Fw and ramA Re for ram $A$. uncB Fw and uncB Re for $u n c B$ were used as the internal control for normalization. A $10 \mathrm{ng}$ of sample of total RNA from K. pneumoniae cells was used as a template for one reaction.

\section{RESULTS AND DISCUSSION}

Gene Cloning We previously cloned many genes responsible for multidrug resistance from chromosomal DNA of $K$. pneumoniae MGH78578. ${ }^{26)}$ One of the candidate plasmids, pETV6, conferred elevated resistance against ethidium bromide, erythromycin, Rhodamine $6 \mathrm{G}$ and so on to drughypersusceptible E. coli KAM32. Since the genome sequence of the $K$. pneumoniae MGH78578 strain was available (website; http://genome.wustl.edu/genome.cgi? GENOME=Klebsiella\%20pneumoniae), we partially sequenced the DNA insert of pETV6 in order to identify the open reading frame(s) (ORFs) responsible for the observed elevated drug resistances. We found that the plasmid pETV6 carries one complete ORF and a part of another ORF (Fig.
1). We found that the complete ORF corresponded to $a c r B$, and truncated one corresponded to acrA (GenBank, ACCESSION No. AJ318073).

We measured the MICs of various antimicrobial agents with E. coli KAM32 carrying or not carrying pETV6. Much higher MIC values were observed with multiple antimicrobial agents including cloxacillin, erythromycin, benzalkonium chloride, ethidium bromide, etc., in E. coli KAM32/pETV6 compared with E. coli KAM32/pSTV28 (control) (Table 3). On the other hand, no change in MICs was detected with ampicillin and kanamycin.

The host $E$. coli KAM32 lacks $a c r B$ but possesses $a c r A .{ }^{19)}$ The plasmid pETV6 possesses the whole $a c r B_{K p}$ gene. Thus, it seemed that $\mathrm{AcrB}_{\mathrm{Kp}}$ and AcrA formed a tripartite complex together with an outer membrane protein, perhaps TolC, of $E$. coli., We tried to clone $a c r A_{K p}$. In fact, we cloned $a c r A_{K p}$ and the promoter region from chromosomal DNA of $K$. pneumoniae MGH78578 by the PCR method, and constructed pETV62 which carries the complete $a c r A_{K p} B_{K p}$ element and its promoter (Fig. 1). We introduced pETV62 into cells of E. coli KAM33 which lacks acrAB. We observed elevated MICs of cloxacillin, erythromycin, benzalkonium chloride, ethidium bromide and so on with $E$. coli KAM33/pETV62 compared with KAM33/pSTV28 (control)

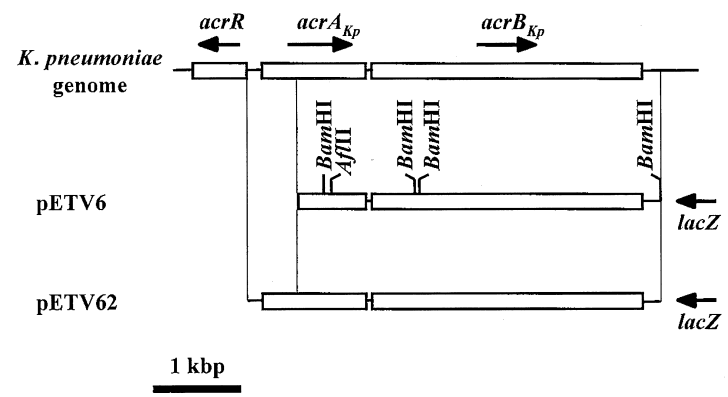

Fig. 1. Regions of $a c r A_{K p} B_{K p}$ Carried by Recombinant Plasmids

The chromosomal DNA region of $K$. pneumoniae MGH78578 including $a c r A_{K p} B_{K_{p}}$ is shown at the top. Recombinant plasmid pETV6 carries the whole $a c r B_{K p}$ gene and a part of $a c r A_{K p}$. The recombinant plasmid pETV62 carries the whole $a c r A_{K p} B_{K p}$ region. The additional region present in pETV62 was cloned by the PCR method. The DNA sequence of the PCR-cloned region was confirmed by sequencing.

Table 3. Drug Susceptibility in E. coli Harboring Each Plasmid

\begin{tabular}{|c|c|c|c|c|}
\hline \multirow{3}{*}{$\begin{array}{l}\text { Antimicrobial } \\
\text { agent }\end{array}$} & \multicolumn{4}{|c|}{$\mathrm{MIC}(\mu \mathrm{g} / \mathrm{ml})$} \\
\hline & \multicolumn{4}{|c|}{ E. coli } \\
\hline & KAM32/pSTV28 & KAM32/pETV6 & KAM33/pSTV28 & KAM33/pETV62 \\
\hline Ampicillin & 2 & 2 & 2 & 4 \\
\hline Cefotaxime & 0.016 & 0.031 & 0.031 & 0.062 \\
\hline Cloxacillin & 2 & 256 & 2 & 512 \\
\hline Oxacillin & 2 & 128 & 1 & 512 \\
\hline Norfloxacin & 0.031 & 0.062 & 0.031 & 0.125 \\
\hline Ofloxacin & 0.031 & 0.062 & 0.031 & 0.25 \\
\hline Erythromycin & 2 & 32 & 4 & 512 \\
\hline Kanamycin & 1 & 1 & 1 & 1 \\
\hline Tetracycline & 1 & 2 & 1 & 4 \\
\hline Acriflavine & 4 & 32 & 4 & 25 \\
\hline Benzalkonium Cl & 16 & 32 & 16 & 32 \\
\hline Ethidium $\mathrm{Br}$ & 8 & 256 & 8 & 1024 \\
\hline Hoechst 33342 & 2 & 16 & 2 & 32 \\
\hline Rhodamine 6G & 16 & 2048 & 8 & 2048 \\
\hline $\operatorname{SDS}^{a)}$ & 256 & $>2048$ & 256 & $>2048$ \\
\hline
\end{tabular}


(Table 3). Likewise, we observed much higher MICs of several antimicrobial agents in E. coli KAM33/pETV62 compared with KAM32/pETV6 (Table 3). There are two possibilities for the higher MICs in E. coli KAM33/pETV62 than in $E$. coli $\mathrm{KAM} 32 / \mathrm{pETV} 6$; 1) $\mathrm{AcrB}_{\mathrm{Kp}}$ fits well with $\mathrm{AcrA}_{\mathrm{Kp}}$ than with AcrA, 2) more $\operatorname{Acr}_{K p} B_{K p}$ complex is formed since more $\mathrm{AcrA}_{\mathrm{Kp}}$ is produced from the multi-copy pETV62 plasmid in E. coli KAM33/pETV62 compared with AcrA produced from chromosomal acrA in E. coli KAM32/ pETV6. To test the interchangeability between the periplasmic component (AcrA or $\operatorname{AcrA}_{\mathrm{Kp}}$ ) and the inner membrane component (AcrA or $\mathrm{AcrB}_{\mathrm{Kp}}$ ), we constructed a series of plasmids carrying either $a c r A_{K p}-a c r B_{K p}, a c r A_{K p}-a c r B$, acr $A$ $a c r B_{K p}$ or $a c r A-a c r B$. These genes were located downstream from tet promoter of pBR322. We measured the MICs of various antimicrobial agents with $E$. coli cells harboring each recombinant plasmid. There were no clear differences, however, in the MICs detected (data not shown). Thus, we conclude that there is a very good interchangeability between the components. Therefore, we conclude that the difference in the MICs between E. coli KAM32/pETV6 and E. coli KAM33/pETV62 is due to the difference in the amount of AcrA $_{\mathrm{Kp}}$ produced in the cells, namely the amount of the $\mathrm{Acr}_{\mathrm{Kp}} \mathrm{B}_{\mathrm{Kp}}$ pump. It seems that the outer membrane component TolC is abundant in E. coli.

We observed no change in the MICs of any antimicrobial agent with $E$. coli KAM33/pETV6 possessing $a c r B_{K p}$ but lacking acr $A$, compared with KAM33/pSTV28 (data not shown). Thus, periplasmic linker (fusion) protein, $\operatorname{AcrA}_{\mathrm{Kp}}$ or AcrA, is necessary for the function of $\mathrm{AcrB}_{\mathrm{Kp}}$.

It should be pointed out that the orientation of $\operatorname{acr} B_{K p}$ is the opposite from that of the lactose promoter in plasmid pETV6. There is no original promoter for the $\operatorname{acr} A_{K p} B_{K p}$ operon in pETV6. This means that some sequence in the acr $A_{K p}$ region functions as a promoter. In fact, we found a promoter-like sequence in the $a c r A_{K p}$ region (about 460 base pairs upstream from the $a c r B_{K p}$ gene) (data not shown).

Ethidium Efflux We tested the efflux activity of AcrA $_{\mathrm{Kp}} \mathrm{B}_{\mathrm{Kp}}$ with E. coli KAM33/pETV62 in comparison to that of E. coli KAM33/pSTV28 (Fig. 2). We observed a much lower intracellular level of ethidium with $E$. coli KAM33/pETV62 compared with that of E. coli KAM33/ pSTV28 under energized conditions, indicating strong efflux activity due to $\mathrm{AcrA}_{\mathrm{Kp}} \mathrm{B}_{\mathrm{Kp}}$ in E. coli KAM33/pETV62. Addition of the $\mathrm{H}^{+}$conductor carbonyl cyanide $m$-chlorophenylhydrazone (CCCP) resulted in a higher level of intracellular ethidium (Fig. 2). The same plateau level was observed with the two types of cells after addition of CCCP. These results support the view that $\mathrm{Acr}_{\mathrm{Kp}} \mathrm{B}_{\mathrm{Kp}}$ functions as an energy-dependent efflux pump, perhaps together with an outer membrane component, TolC, in E. coli cells.

An Outer Membrane Component for the Pump The RND-type multidrug efflux pumps are tripartite. The plasmid pETV62 carries no gene for an outer membrane protein. It is likely that $\mathrm{AcrA}_{\mathrm{Kp}} \mathrm{B}_{\mathrm{Kp}}$ utilizes TolC of E. coli as the outer membrane component when functioning as a drug efflux pump in $E$. coli cells. We tested this possibility by introducing pETV63, a pBR322-based plasmid carrying $\operatorname{acr} A_{K p} B_{K p}$ (Table 1), into cells of $E$. coli KAM43 which lacks tolC and $\operatorname{acr} A B$. We observed no increases in the MICs of erythromycin and others with $E$. coli KAM43/pETV63 compared with

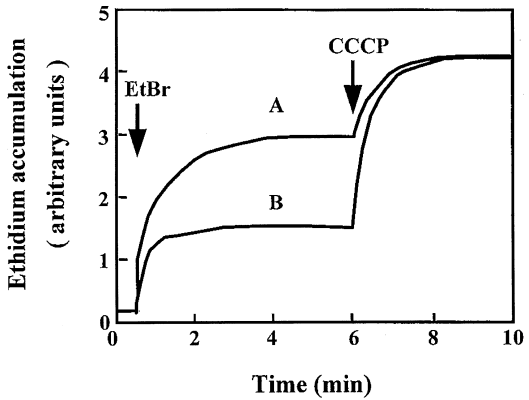

Fig. 2. Energy-Dependent Ethidium Efflux Due to $\operatorname{Acr}_{\mathrm{Kp}} \mathrm{B}_{\mathrm{Kp}}$

Ethidium efflux in cells was monitored continuously by measuring the fluorescence of ethidium. The assay was performed in the presence of potassium lactate as a respiratory substrate. At the time-point indicated by the first downward arrow, ethidium bromide (EtBr) was added at $10 \mu \mathrm{M}$ to the cell suspension. At the time-point indicated by the second arrow, CCCP was added at $100 \mu \mathrm{M}$. A, E. coli KAM33/pSTV28 (control); B E. coli $\mathrm{KAM} 33 / \mathrm{pETV} 62$

Table 4. MICs of Several Antimicrobial Agents

\begin{tabular}{|c|c|c|c|c|c|}
\hline \multirow{4}{*}{$\begin{array}{c}\text { Antimicrobial } \\
\text { agent }\end{array}$} & \multicolumn{5}{|c|}{$\operatorname{MIC}(\mu \mathrm{g} / \mathrm{ml})$} \\
\hline & \multicolumn{5}{|c|}{ E. coli KAM43 } \\
\hline & /pBR322 & /pETV63 & /pETV63 & /pBR322 & /pETV63 \\
\hline & /pSTV28 & /pSTV28 & /pSET2 & /pKTC44 & /pKTC44 \\
\hline Erythromycin & 2 & 2 & 128 & 4 & 128 \\
\hline Acriflavine & 2 & 2 & 128 & 2 & 128 \\
\hline Ethidium $\mathrm{Br}$ & 2 & 2 & 512 & 4 & 1024 \\
\hline Kanamycin & 1 & 1 & 1 & 1 & 1 \\
\hline
\end{tabular}

E. coli KAM43 harboring two of the following plasmids were used for MIC testing; pETV63 (carrying $a c r A_{K p} B_{K p}$ genes of $K$. pneumoniae), pKTC44 (carrying kocC gene of $K$. pneumoniae), pSET2 (carrying tolC gene of E. coli), pBR322 (vector) or pSTV28 (vector).

E. coli KAM43/pSTV28 (control) (Table 4). An additional introduction of pSET2, a pSTV28-based plasmid carrying tol $C$, into cells of $E$. coli KAM43/pETV63 resulted in a great increase in the MICs of erythromycin, acriflavine and ethidium bromide (Table 4). Thus, it is clear that TolC of E. coli is necessary for $\mathrm{Acr}_{\mathrm{Kp}} \mathrm{B}_{\mathrm{Kp}}$ to function as a multidrug efflux pump in $E$. coli cells.

These results suggest that an outer membrane component is necessary for $\mathrm{AcrA}_{\mathrm{Kp}} \mathrm{B}_{\mathrm{Kp}}$ to function as a pump in cells of $K$. pneumoniae. There is no putative gene for an outer membrane component next to the $\operatorname{acr} A_{K p} B_{K p}$ locus in the chromosome of $K$. pneumoniae. Thus, we searched for gene(s) as candidates for $\operatorname{ortholog}(\mathrm{s})$ of TolC in the genome sequence of $K$. pneumoniae (http://genome.wustl.edu/genome.cgi? GENOME=Klebsiella\%20pneumoniae). We found one putative gene for an outer membrane component, the deduced amino acid sequence of which showed high identity $(83 \%)$ and similarity (98\%) with TolC of E. coli. We cloned the gene from the chromosomal DNA of $K$. pneumoniae MGH78578 by the PCR method, and designated the gene as $k o c C$. The $k o c C$ gene is located just downstream from the lac promoter in a plasmid pKTC44. We tested whether KocC was able to function with $\mathrm{Acr}_{\mathrm{Kp}} \mathrm{B}_{\mathrm{Kp}}$. Plasmid pETV63 carrying $\operatorname{acr} A_{K p} B_{K p}$ and pKTC44 carrying kocC were co-introduced into cells of $E$. coli KAM43 lacking acrAB and tolC. E. coli $\mathrm{KAM} 43 / \mathrm{pETV} 63 / \mathrm{pKTC} 44$ showed greatly increased MICs of erythromycin, acriflavine and ethidium bromide (Table 4). Thus, we conclude that $\mathrm{AcrA}_{\mathrm{Kp}} \mathrm{B}_{\mathrm{Kp}}$ can utilize $\mathrm{KocC}$ as an outer membrane component and can extrude 
erythromycin and others from cells. It is highly likely that the $\mathrm{AcrA}_{\mathrm{Kp}} \mathrm{B}_{\mathrm{Kp}}$-KocC tripartite complex functions as a multidrug efflux pump in cells of $K$. pneumoniae. E. coli KAM43/pETV63/pSTV28 lacking the outer membrane component showed no increase in the MICs. Cells of $E$. coli KAM43/pETV63/pKTC44 (possessing $a c r A_{K p} B_{K p}$ and $k o c C$ ) and $E$. coli KAM43/pETV63/pSET2 (possessing $\operatorname{acr} A_{K p} B_{K p}$ and tolC) showed almost the same MIC values. Thus, we conclude that TolC from E. coli can be completely substituted with KocC from $K$. pneumoniae for the function of the drug efflux pump $\mathrm{AcrA}_{\mathrm{Kp}} \mathrm{B}_{\mathrm{Kp}}$ at least in E. coli cells.

We detected small but reproducible increases in the MICs of erythromycin and ethidium bromide with $E$. coli KAM43/pKTC44/pBR322 compared with E. coli KAM43/ pSTV28/pBR322 (Table 4). This suggests that KocC can be utilized as an outer membrane component by some drug efflux pump(s) remaining in E. coli KAM43.

The three dimensional (3D) structure of the TolC protein has been reported. ${ }^{31)}$ We compared the $3 \mathrm{D}$ structure of TolC and that of deduced KocC using a computer software package (Swiss-PdbViewer). The 3D structure of TolC and the deduced 3D structure of KocC were very similar (data not shown). The amino acid sequence of the region of TolC that is the interaction site with $\mathrm{AcrB}^{11,31,32)}$ was identical in $\mathrm{KocC}$ (data not shown). This supports the view that the interchangeability between TolC and $\mathrm{KocC}$ is very high.

We measured mRNA expression of kocC by the RT-PCR method, and found that kocC was expressed well in cells of K. pneumoniae MGH78578. We found a promoter-like sequence in a region just upstream of the kocC gene. Its expression level was almost same as that of a house-keeping gene $u n c B$, which codes for the $\beta$ subunit of the $\mathrm{H}^{+}$-translocating ATPase (data not shown).

Expression Level of $\boldsymbol{a c r} A_{K p} B_{K p}$ in $K$. pneumoniae $K$. pneumoniae MGH78578, a clinically isolated strain, showed higher MICs of many antimicrobial agents as reported previously. ${ }^{26)}$ On the other hand, the MICs observed in a strain obtained from American Type Culture Collection, K. pneumoniae ATCC10031, were not high. ${ }^{26)}$ We investigated whether the higher MICs in MGH78578 were due to elevated expression of the $\operatorname{acr} A_{K p} B_{K p}$. Expression of $a c r A_{K p}$ in MGH78578 was about 2.2-fold higher than that in ATCC10031 (Fig. 3A). This elevated $a c r A_{K p}$ expression may be related to some extent to the elevated MICs of multiple antimicrobial agents in MGH78578. It seems also possible that there are some changes in amino acid sequence between $\operatorname{Acr}_{\mathrm{Kp}} \mathrm{B}_{\mathrm{Kp}}$ from MGH78578 and that from ATCC10031. We are now testing this possibility by sequencing the $a c r A_{K p} B_{K p}$ from ATCC10031. It should be noted that the band corresponding to $\operatorname{acr} A_{K p}$ was easily detected by RT-PCR analysis even in ATCC10031 cells, indicating that the $\operatorname{acr} A_{K p} B_{K p}$ operon is expressing well in cells of $K$. pneumoniae under normal growth conditions. As in the case of E. coli, it seems that $\mathrm{AcrA}_{\mathrm{Kp}} \mathrm{B}_{\mathrm{Kp}}$ is a principal multidrug efflux pump in $K$. pneumoniae and contributes to intrinsic drug resistance of this microorganism.

Schneiders et al. reported that mutation or deletion of $a c r R_{K p}$, a regulatory gene for $a c r A_{K p} B_{K p}$, resulted in increased resistance against fluoroquinolones. ${ }^{33)}$ There was no deletion in the corresponding region of $a c r R_{K p}$ of K. pneumoniae MGH78578. We found that there were 7 amino acid re-
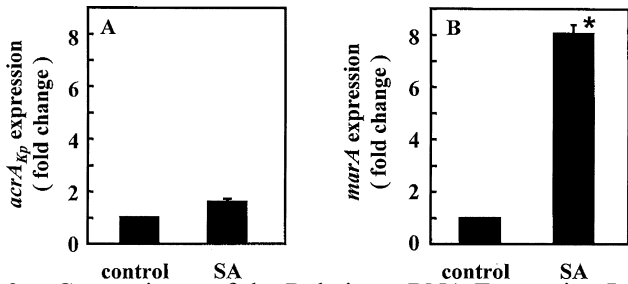

Fig. 3. Comparisons of the Relative mRNA Expression Levels of acr $A_{K p}$, marA and ramA between K. pneumoniae ATCC10031 and MGH78578

The expression was determined by the real time RT-PCR method. Relative quantification of the target gene expression was normalized with the mRNA expression of an endogenous reference gene, $u n c B$. Panel A; $a c r A_{K p}$ Panel B; marA, Panel C; $\operatorname{ram} A$. The data represent mean \pm S.D. of four separate experiments. Statistical significance was determined by use of Student's t-test. $* p<0.05$; significantly different from the value of ATCC10031.
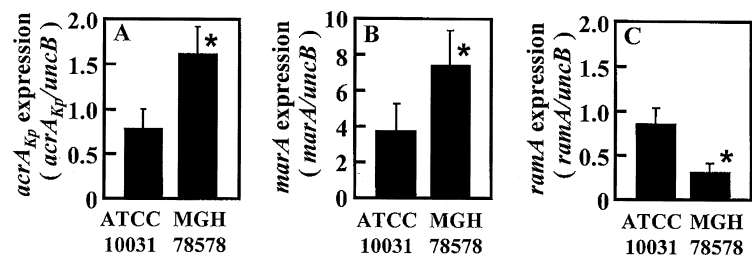

Fig. 4. Effect of Salicylic Acid on the Expression of $a c r A_{K p}$ and $\operatorname{mar} A$ in K. pneumoniae MGH78578

The expression was determined by the real time RT-PCR method. Relative levels of expression of $a c r A_{K p}(\mathrm{~A})$ and $\operatorname{marA}(\mathrm{B})$ in comparison with the expression in the control (expression in the absence of salicylic acid) are shown. Salicylic acid (SA) was added at $128 \mu \mathrm{g} / \mathrm{ml}$. Salicylic acid at this concentration gave no effect on the growth of $K$. pneumoniae MGH78578. The data represent mean \pm S.D. of four separate experiments. $* p<0.05$; significantly different from the control value.

placements between the primary sequence of $\mathrm{AcrR}_{\mathrm{Kp}}$ reported by Domenech-Sanchez et al. ${ }^{24)}$ (ACCESSION No.AJ318073) and that deduced in MGH78578. Interestingly, all of the 7 replaced residues in $\mathrm{AcrR}_{\mathrm{Kp}}$ of MGH78578 strain were identical with those in $\mathrm{AcrR}_{\mathrm{Kp}}$ in one resistant mutant reported by Schneiders et al. ${ }^{33)}$ Thus, AcrR $_{\mathrm{Kp}}$ of MGH78578 is a mutant type one reported by them. It is likely that $\mathrm{AcrR}_{\mathrm{Kp}}$ in MGH78578 is less active as a repressor than that of wild type, and results in elevated expression of the $a c r A_{K p} B_{K p}$ operon in MGH78578 than in ATCC10031.

MarA is a positive regulator for the $\operatorname{acr} A B$ operon in $E$. coli. ${ }^{34)}$ We investigated whether the expression of the marA ortholog $\left(\operatorname{mar} A_{K p}\right)$ was more elevated in $K$. pneumoniae MGH78578 than in ATCC10031. We detected about 2.3 times higher expression of $\operatorname{mar}_{K p}$ in the MGH strain than in the ATCC strain (Fig. 3B). Thus, MarA may positively regulate the expression of the $\operatorname{acr} A_{K p} B_{K p}$ operon in $K$. pneumoniae. It has been reported that the expression of $\operatorname{mar} A$ was greatly enhanced by salicylic acid in $E$. coli. ${ }^{35)}$ We observed about 8-fold increase in the expression of $\operatorname{mar}_{K p}$ by adding salicylic acid to growth medium in $K$. pneumoniae (Fig. 4). However, only a small increase in the expression of $a c r A_{K p}$ was observed when salicylic acid was added to the growth medium (Fig. 4). Schneiders et al. reported that an increase in the expression of $\operatorname{mar}_{K p}$ was not observed with a clinically isolated fluoroquinolone-resistant strain of K. pneumoniae that also showed elevated resistance against organic solvents. $^{33)}$ Thus, the effect of $\operatorname{mar}_{K p}$ on the regulation of $\operatorname{acr}_{K p} B_{K p}$ expression in $K$. pneumoniae may be different from that in $E$. coli.

It has been reported that the expression of $\operatorname{ram} A$, a regula- 
tory gene, was enhanced in a multidrug resistant strain of $K$. pneumoniae. ${ }^{36)}$ It has been also reported that expression of $a c r A_{K p}$ was elevated in a strain of $K$. pneumoniae in which the expression of $\operatorname{ram} A$ was increased. ${ }^{33)}$ RamA is involved in the expression of acr $A B$ in Enterobacter aerogenes and is closely related to $K$. pneumoniae. RamA of $E$. aerogenes enhances the expression of $\operatorname{mar} A$, and an increase in RamA expression results in the enhanced expression of acrAB even in a marA-deleted strain. ${ }^{37)}$ Both RamA and MarA belong to the AraC-XylS transcriptional activator family. ${ }^{36,38)}$ It is not clear whether RamA is involved in the regulation of $a c r A B$ in $K$. pneumoniae. For these reasons, we also measured the expression level of $\operatorname{ram} A$ (Fig. 3C). The $\operatorname{ram} A$ expression level in $K$. pneumoniae MGH78578 was about 4-fold lower rather than in $K$. pneumoniae ATCC10031. Thus, it is not clear at the present time whether RamA is involved in the regulation of acr $A B$ expression in $K$. pneumoniae or not.

It was reported that the expression of $\operatorname{acr} A B$ was elevated by induction with several antimicrobial agents in $E$. coli ${ }^{35,39)}$ Morita et al. in our laboratory previously reported that expression of mexCD of Pseudomonas aeruginosa was induced by several antimicrobial agents. ${ }^{40)}$ Although we tested the effect of many antimicrobial agents on the expression of acr $A_{K p} B_{K p}$ in $K$. pneumoniae MGH78578, we observed only a small increase in the level of expression (data not shown). Thus, it seems that $a c r A_{K p} B_{K p}$ is not an inducible operon in K. pneumoniae MGH78578.

Acknowledgments We thank Dr. Michael McClelland of the Sidney Kimmel Cancer Center for providing us with K. pneumoniae MGH78578 and Dr. Manuel Varela of Eastern New Mexico University for critically reading the manuscript. This research was supported in part by a Grant-in-Aid for Scientific Research from the Ministry of Education, Culture, Sports, Science and Technology of Japan.

\section{REFERENCES}

1) Struve C., Krogfelt K. A., Environ. Microbiol., 6, 584-590 (2004).

2) Varon N. F., Alangaden G. J., Expert. Rev. Anti. Infect. Ther, 2, 95109 (2004).

3) Paterson D. L., Am. J. Med., 119, S20-S28; discussion S62-S70 (2006).

4) Nikaido H., Clin. Infect. Dis., 27 (Suppl. 1), S32-S41 (1998).

5) Piddock L. J., Clin. Microbiol. Rev., 19, 382-402 (2006).

6) Ma D., Cook D. N., Alberti M., Pon N. G., Nikaido H., Hearst J. E., J. Bacteriol., 175, 6299-6313 (1993).

7) Giraud E., Cloeckaert A., Kerboeuf D., Chaslus-Dancla E., Antimicrob. Agents Chemother, 44, 1223-1228 (2000).

8) Morita Y., Komori Y., Mima T., Kuroda T., Mizushima T., Tsuchiya T., FEMS Microbiol. Lett., 202, 139-143 (2001).

9) Okusu H., Ma D., Nikaido H., J. Bacteriol., 178, 306-308 (1996).

10) Nikaido H., Zgurskaya H. I., J. Mol. Microbiol. Biotechnol., 3, 215218 (2001)
11) Murakami S., Nakashima R., Yamashita E., Yamaguchi A., Nature (London), 419, 587—593 (2002)

12) Murakami S., Nakashima R., Yamashita E., Matsumoto T., Yamaguchi A., Nature (London), 443, 173-179 (2006).

13) Fralick J. A., J. Bacteriol., 178, 5803-5805 (1996).

14) Ramos J. L., Duque E., Gallegos M. T., Godoy P., Ramos-Gonzalez M. I., Rojas A., Teran W., Segura A., Annu. Rev. Microbiol., 56, 743-768 (2002).

15) Mazzariol A., Cornaglia G., Nikaido H., Antimicrob. Agents Chemother., 44, 1387-1390 (2000).

16) Nishino K., Yamada J., Hirakawa H., Hirata T., Yamaguchi A., Antimicrob. Agents Chemother, 47, 3030-3033 (2003).

17) Ma D., Alberti M., Lynch C., Nikaido H., Hearst J. E., Mol. Microbiol., 19, 101-112 (1996).

18) Moken M. C., McMurry L. M., Levy S. B., Antimicrob. Agents Chemother, 41, 2770-2772 (1997).

19) Chen J., Kuroda T., Huda M. N., Mizushima T., Tsuchiya T., J. Antimicrob. Chemother, 52, 176-179 (2003).

20) Kumar A., Worobec E. A., Antimicrob. Agents Chemother, 49, 14951501 (2005).

21) Lacroix F. J., Cloeckaert A., Grepinet O., Pinault C., Popoff M. Y., Waxin H., Pardon P., FEMS Microbiol. Lett., 135, 161-167 (1996).

22) Burse A., Weingart H., Ullrich M. S., Mol. Plant Microbe Interact., 17, 43-54 (2004).

23) Masi M., Pages J. M., Villard C., Pradel E., J. Bacteriol., 187, 3894 3897 (2005).

24) Domenech-Sanchez A., Alberti S., Martinez-Martinez L., Pascual A., Garcia I., Benedi V. J., Abstr. 41st Intersci. Conf. Antimicrob. Agents Chemother., abstr. C1-2018, p. 104, 2001

25) Mazzariol A., Zuliani J., Cornaglia G., Rossolini G. M., Fontana R., Antimicrob. Agents Chemother., 46, 3984-3986 (2002).

26) Ogawa W., Li D. W., Yu P., Begum A., Mizushima T., Kuroda T., Tsuchiya T., Biol. Pharm. Bull., 28, 1505-1508 (2005).

27) Datsenko K. A., Wanner B. L., Proc. Natl. Acad. Sci. U.S.A., 97, $6640-6645$ (2000).

28) Matsuo T., Hayashi K., Morita Y., Koterasawa M., Ogawa W., Mizushima T., Tsuchiya T., Kuroda T., Microbiology, 153 (Pt 12), 4129-4137 (2007).

29) Japan Society of Chemotherapy, Chemothererapy (Tokyo), 38, 103105 (1990)

30) Ogawa W., Koterasawa M., Kuroda T., Tsuchiya T., Biol. Pharm. Bull., 29, 550-553 (2006).

31) Koronakis V., Sharff A., Koronakis E., Luisi B., Hughes C., Nature (London), 405, 914-919 (2000).

32) Gerken H., Misra R., Mol. Microbiol., 54, 620-631 (2004).

33) Schneiders T., Amyes S. G., Levy S. B., Antimicrob. Agents Chemother., 47, 2831-2837 (2003).

34) Alekshun M. N., Levy S. B., Antimicrob. Agents Chemother., 41, 2067-2075 (1997).

35) Pomposiello P. J., Bennik M. H., Demple B., J. Bacteriol., 183, 3890 $3902(2001)$.

36) George A. M., Hall R. M., Stokes H. W., Microbiology, 141 (Pt8), 1909-1920 (1995)

37) Chollet R., Chevalier J., Bollet C., Pages J. M., Davin-Regli A., Antimicrob. Agents Chemother, 48, 2518-2523 (2004).

38) Cohen S. P., Hachler H., Levy S. B., J. Bacteriol., 175, 1484-1492 (1993).

39) Rosenberg E. Y., Bertenthal D., Nilles M. L., Bertrand K. P., Nikaido H., Mol. Microbiol., 48, 1609-1619 (2003).

40) Morita Y., Murata T., Mima T., Shiota S., Kuroda T., Mizushima T., Gotoh N., Nishino T., Tsuchiya T., J. Antimicrob. Chemother, 51, 991-994 (2003). 